\title{
Heat-fluid-solid coupling model for gas-bearing coal seam and numerical modeling on gas drainage promotion by heat injection
}

\author{
Ruifu Yuan ${ }^{1,2}\left(\mathbb{D} \cdot\right.$ Chunling Chen $^{1} \cdot \mathrm{Xiao}_{\mathrm{Wei}}{ }^{1} \cdot \mathrm{Xiaojun}_{\mathrm{Li}^{1}}$
}

Received: 24 February 2019/Revised: 18 July 2019/Accepted: 2 August 2019/Published online: 21 August 2019

(C) The Author(s) 2019

\begin{abstract}
Improving the absorbed gas to active desorption and seepage and delaying gas drainage attenuation are considered as key methods for increasing drainage efficiency and gas output. According to the solid mechanics theory, the nonlinear Darcy seepage theory and thermodynamics, the heat-fluid-solid coupling model for gassy coal has been improved. The numerical model was founded from the improved multi-field coupling model by COMSOL Multiphysics and gas drainage by borehole down the coal seam enhanced by heat injection was modelled. The results show that the heatfluid-solid model with adsorption effects for gassy coal was well simulated by the improved multi-field model. The mechanism of coal seam gas desorption seepage under the combined action of temperature, stress and adsorption can be well described. Gas desorption and seepage can be enhanced by heat injection into coal seams. The gas drainage rate was directly proportional to the temperature of injected heat in the scope of $30-150{ }^{\circ} \mathrm{C}$ and increasing in the whole modelled drainage process $(0-1000 \mathrm{~d})$. The increased level was maximum in the initial drainage time and decreasing gradually along with drainage time. The increasing ratio of drainage rate was maximum when the temperature raised from 30 to $60{ }^{\circ} \mathrm{C}$. Although the drainage rate would increase along with increasing temperature, when exceeding $60{ }^{\circ} \mathrm{C}$, the increasing ratio of drainage rate with rising temperature would decrease. Gas drainage promotion was more effective in coal seams with lower permeability than with higher permeability. The coal seam temperature in a $5 \mathrm{~m}$ distance surrounding the heat injection borehole would rise to around $60{ }^{\circ} \mathrm{C}$ in 3 months. That was much less than the time of gas drainage in the coal mines in sites with low permeability coal seams. Therefore, it is valuable and feasible to inject heat into coal seams to promote gas drainage, and this has strong feasibility for coal seams with low permeability which are widespread in China.
\end{abstract}

Keywords Gassy coal $\cdot$ Heat-fluid-solid coupling model $\cdot$ Heat injection $\cdot$ Gas extraction $\cdot$ Numerical modeling

\section{Introduction}

Gas (coalbed methane) extraction from low permeability coal seams has been always a difficult problem for prevention gas disaster in underground coal mine and utilization of coal mine gas in the world (Yuan 2015; Li and

Ruifu Yuan

yrf@hpu.edu.cn

1 School of Energy Science and Engineering, Henan Polytechnic University, Jiaozuo 454003, China

2 Collaborative Innovation Center of Coal Work Safety of Henan Province, Jiaozuo 454003, China
Fang 2014; Esterhuyse 2017). The variation of gas flow in low permeability coal seam is mastered under the impact of multiple factors such as gas, stress and temperature. This has a great significance to study the theory and technology for efficient coal seam gas extraction.

Many previous researches have proven that coal is a porous material with a large internal surface area, and it physically adsorbs gas. The adsorption and desorption processes for gas are basically reversible, and the higher the temperature is, the lower the adsorption quantity of gas (Zhang et al. 2013). At present, technical means were used to improve the gas extraction efficiency of low permeability coal seams, such as pressure relief extraction, 
hydraulic punching, hydraulic fracturing, etc. (Uth 2014). The principles of reducing the influence of ground stress and increasing the local permeability of coal seams are involved in improving the extraction efficiency in a short time. However, the attenuation of extraction rate is faster, especially in soft coal seams. Due to artificial fractures closing quickly under stress, the permeability decreases rapidly. Therefore, new technical ways should be found to improve the gas desorption and seepage velocity and delay the gas extraction rate attenuation in low permeability coal seams.

Drawing on the heat injection technology in the petroleum industry, the idea was putting forward the increasing of coal seam temperature by injecting heat to accelerate and increase gas production. The study found that raising the coal seam temperature can accelerate the desorption and releasing of adsorbed gas and increase the seepage rate of gas in coal seam fissures, which may become an effective method to promote gas extraction efficiency (Shahtalebi et al. 2016; Zhao et al. 2018; Teng et al. 2018). Previous research showed that some experimental and theoretical studies on the influence of temperature on coal seam gas adsorption and seepage have achieved many valuable results. Anderson et al. (2011) studied the influence of temperature on its $a$ and $b$ values using Langmuir adsorption theory and analyzed the changes in the $a$ and $b$ values below $200{ }^{\circ} \mathrm{C}$. The coal desorption and permeability change under the coupling condition of temperature and stress fields was carried out by Li et al. (2009a, b) to establish the seepage control equation and obtain the gas desorption and seepage change mechanism with the increase in temperature. The influence of temperature change on the initial speed of methane emission was studied, and the result indicated that the relation between emission and temperature showed a proportional to quadratic function (Tailakov et al. 2015). The studies of the characteristics of methane desorption in coal under uniaxial stress and temperature concluded that temperature rise was a key reason for the large amount of desorption of adsorbed gas (Wang et al. 2013). Zhu et al. (2013) carried out research on the mechanical properties of coal samples for gas adsorption under the influence of temperature changes. It is believed that the adsorption capacity of coal samples was directly affected by the temperature changes, resulting in an increase in free gas content, thus reducing the strength of coal containing gas as a whole. Yin et al. (2013) and Zhang et al. (2018b) carried out permeability experiments to change the stress and temperature conditions of coal samples and discovered that permeability decreasing in the scope of $0-80{ }^{\circ} \mathrm{C}$, while increasing sharply when the temperature exceed $80{ }^{\circ} \mathrm{C}$. The COMSOL software was used to numerically simulate the solid-gas-heat coupling effect of gas-bearing coal \& rock masses and obtained the gas seepage mechanism near the heading face but did not consider the temperature effect ( $\mathrm{Li}$ et al. 2017). Ju et al. (2016) and Alam et al. (2015) tested the change mechanism of permeability under the change in temperature (below $80{ }^{\circ} \mathrm{C}$ ) and confining pressure and believed that the increase in temperature will expand the coal matrix, resulting in pore closures and a decrease impermeability. Zhang et al. (2018a) introduced the theory of coal \& gas two-state adsorption heat, constructed the control equation for the coal seam temperature field, improved the heatfluid-solid coupling mathematical model of coal seam gas flow, and theoretically explained the interaction mechanism of adsorption and desorption, stress, temperature and seepage fields in the process of coal seam gas flow. Shan and Lai (2018) conducted seepage tests under different temperatures and pore pressures. It was believed that the increase in pore pressure can reduce permeability to a certain extent whereas the increase in temperature increases permeability. Wang et al. (2015) carried out experiments on the variation of coal sample permeability under different temperatures and axial pressures. It was concluded that the increase in axial strain will obviously reduce the permeability, and the reduce rate will gradually decrease with the increase in strain. The influence of temperature on permeability was related to the stress state inside the coal sample.

The above research results further prove that temperature has an important influence on gas adsorption and seepage flow. However, the coupling theory considering the heat-fluid-solid coupling and gas adsorption-desorption effects still needs improvement. In addition, there were few studies on the extraction of gas by injecting heat into coal seams close to the in-site conditions. Therefore, this paper aimed at the in-site conditions of coal heat injection and gas extraction, the heat-fluid-solid coupling model of gas-bearing coal was improved, and the variation state and extraction efficiency of coal seam gas were studied based on the actual conditions of low permeability coal seams after injecting heat by using numerical simulation.

\section{Mathematical model of heat-fluid-solid coupling for gas-bearing coal}

Coal seams contain complex fissures and pores of different scales resulting in rich adsorption potential. A large number of gas molecules are adsorbed in the cracks and pores of coal. Coal seam temperature and stress interact with gas desorption and seepage coupling. The heat-fluid-solid coupling model of coal-containing gas needs to fully consider the changes in coal permeability and gas flow under the influence of multiple factors. 


\subsection{Fundamental assumptions}

In order to make the three-field coupled seepage model of gas-bearing coal easy to calculate, the following assumptions were made:

(1) A coal seam is a uniform porous material with pores and fissures;

(2) Gas drainage has little influence on the overall deformation of a coal seam;

(3) The temperature change in the seepage process does not affect the gas dynamic viscosity;

(4) The free gas in the coal seam satisfies the ideal gas state;

(5) The coal matrix at any point in the coal seam is consistent with the gas temperature;

(6) The pore pressure is consistent with the gas pressure in the fissures;

(7) The influence of moisture on coal bed adsorption and seepage can be ignored.

\subsection{Coal deformation control equation}

The deformation field equation includes the solid balance, geometric and constitutive equations of a coal body under gas adsorption deformation. For the coal body that adsorbs gas, its variation control equation is:

\section{(1) Solid equilibrium equation}

According to the theory of elastic mechanics, the expression form of the equation was:

$\sigma_{i j, j}+f_{i}=0 \quad(i=1,2,3 ; j=1,2,3)$

where $\sigma_{i j}$ was the component of the stress tensor (N) and $f_{i}$ was the component of volumetric force $(\mathrm{N})$.

\section{(2) Geometric equation}

The strain and displacement components should satisfy the geometric equation:

$\varepsilon_{i j}=\frac{1}{2}\left(u_{i, j}+u_{j, i}\right)$

where $\varepsilon_{i j}$ was the strain tensor component and $u_{i}$ was the displacement component $(\mathrm{m})$.

(3) Constitutive equation of a coal body considering deformation of adsorbed gas

According to the elastic theory of porous media, the constitutive equation of coal considering gas adsorption deformation was (Wei 2012):

$$
\begin{aligned}
\varepsilon_{i j}= & \frac{1}{2 G} \sigma_{i j}-\left(\frac{1}{6 G}-\frac{1}{9 K}\right) \sigma_{k k} \delta_{i j}+\frac{\alpha}{3 K} p \delta_{i j}+\frac{\varepsilon_{s}}{3} \delta_{i j} \\
& +\frac{\alpha_{s} \Delta T}{3} \delta_{i j}
\end{aligned}
$$

where $G$ was the shear modulus $(\mathrm{Pa}) ; \delta_{i j}$ was the Kronecker symbol $(i, j=1,2,3)$; $A$ was the Biot coefficient, $\alpha=1-k / k_{s} ; k_{s}$ was the bulk modulus of the coal skeleton $(\mathrm{Pa}) ; K$ was the bulk modulus of $\operatorname{coal}(\mathrm{Pa}) ; \sigma_{k k}=\sigma_{11}$ $+\sigma_{22}+\sigma_{33}$ was the normal stress component; $\alpha_{s}$ was the coefficient of thermal expansion $\left({ }^{\circ} \mathrm{C}^{-1}\right) ; \Delta T$ was the temperature increment; $p$ was the gas pressure; $\varepsilon_{s}$ was the coal body strain caused by gas adsorption, and the expression was:

$\varepsilon_{S}=\frac{\varepsilon_{L} b}{1+b p}$

where $\varepsilon_{L}$ was the gas adsorption volume strain and $b$ was the gas adsorption pressure constant.

Equations (1), (2), (3) and (4) were combined to obtain Navier-type equations, that was, a coal deformation control equation considering gas adsorption:

$$
\begin{aligned}
& G u_{i, k k}+\frac{G}{1-2 v} u_{k, k i}-\alpha_{S} K T_{i}-\alpha p_{i}-K \frac{\varepsilon_{L} b}{(1+b p)^{2}} p_{i}+f_{i} \\
& \quad=0
\end{aligned}
$$

\subsection{Gas seepage control equation}

\subsubsection{Coupling relationship among three fields}

The literature established a three-field coupling relationship on the assumption that the coal matrix was a uniform block (Alam et al. 2015), and the specific process was as follows. The porosity in coal was closely related to its deformation, showing a positive or negative relationship. $V_{s}$ was the volume of the coal skeleton $\left(\mathrm{m}^{3}\right)$, and $V_{p}$ was the coal body pore volume $\left(\mathrm{m}^{3}\right)$, so the total coal body volume is $V=V_{s}+V_{p}$, and the porosity was:

$\varphi=\frac{V_{p}}{V}$

Adsorption of gas makes the coal expansion strain consistent with the change in matrix block bulk strain. Homogeneous pressure $s$ and gas pressure $p$ borne by the coal body were used to express the constitutive equation of volume strain $\Delta V / V$ and pore volume strain $\Delta V_{p} / V_{p}$ of the coal matrix block:

$$
\begin{aligned}
& \frac{\Delta V}{V}=-\frac{1}{K_{m}}(\Delta \bar{\sigma}-\alpha \Delta p)+\alpha_{s} \Delta T+\Delta \varepsilon_{s} \\
& \frac{\Delta V_{p}}{V_{p}}=-\frac{1}{K_{p}}(\Delta \bar{\sigma}-\beta \Delta p)+\alpha_{s} \Delta T+\Delta \varepsilon_{s}
\end{aligned}
$$


$A$ was still the Biot coefficient of the coal matrix, $\alpha=1-K / K_{s} . \beta$ was the Biot coefficient of the coal body matrix pores, and $\beta=1-K_{p} / K_{s}$. $K_{p}$ was the bulk modulus of pore gas $(\mathrm{Pa})$. The average compressive stress $\bar{\sigma}$ was

$\bar{\sigma}=-\frac{\sigma_{11}+\sigma_{22}+\sigma_{33}}{3}$

According to the Betti-Maxwell reciprocity theorem, it was calculated that:

$K_{p}=\frac{\phi_{m}}{\alpha} K_{m}$

where $K_{m}$ represented the pore gas modulus.

Available from Eqs. (6)-(10):

$\phi_{m}-\phi_{m 0}=\left(\alpha-\phi_{m}\right)\left(\Delta \varepsilon_{v}+\frac{1}{K_{s}} \Delta p-\alpha_{s} \Delta T-\Delta \varepsilon_{s}\right)$

Let

$$
\begin{aligned}
M & =\varepsilon_{v}+\frac{1}{K_{s}} p-\varepsilon_{s}-\alpha_{s} T M_{0} \\
& =\varepsilon_{v 0}+\frac{1}{K_{s}} p_{0}-\varepsilon_{L} p_{0} /\left(p_{0}+p_{L}\right)-\alpha T_{o}
\end{aligned}
$$

The above equation was simplified to:

$\frac{\phi_{m}}{\phi_{m 0}}=\frac{\left[\left(1+M_{0}\right)+\alpha\left(M-M_{0}\right) / \phi_{m 0}\right]}{1+M}$

The permeability of available coal seams was:

$\frac{k_{m}}{k_{m 0}}=\left(\frac{\left[\left(1+M_{0}\right)+\alpha\left(M-M_{0}\right) / \phi_{m 0}\right]}{1+M}\right)^{3}$

where $k_{m 0}$ was the initial coal seam permeability.

\subsubsection{Seepage control equation}

The gas seepage mass balance equation in a coal body was:

$\frac{\partial m}{\partial t}+\nabla \cdot\left(\rho_{g} \vec{q}_{g}\right)=I$

where $\rho_{g}$ was the density of gas in coal seam fissures, $\mathrm{kg} /$ $\mathrm{m}^{2} ; T$ was time, $\mathrm{s} ; I$ was the gas source. $m$ was the mass of gas in a unit volume of the coal seam, $\mathrm{kg}$; $q_{g}$ was the Darcy velocity vector, $\mathrm{m} / \mathrm{s}$. This equation ignored the gravity of gas, and its expression was:

$\vec{q}_{g}=-\frac{k}{\mu} \nabla p$

where $k$ was the gas permeability in a coal seam; $\mu$ was the viscosity coefficient of gas in a coal seam, $\mathrm{N} \mathrm{s} / \mathrm{m}^{2}$.

The total mass of free gas in coal adsorption and fissures was $m$. The gas quality of the two parts was calculated separately, and the free gas quality in the crack was: $m_{\mathrm{f}}=\rho_{\mathrm{g}} \phi$

where $m_{f}$ was the mass of free gas in the fractures, $\mathrm{kg}$; and $\phi$ was the coal body porosity. According to the ideal gas state equation, the density of free gas could be expressed as:

$\rho_{\mathrm{g}}=\frac{M_{g}}{R T} p$

where $M_{g}$ was the gas molecule molar mass; $R$ was Pussler's gas constant of $8.31 \mathrm{~J} /(\mathrm{mol} \mathrm{K})$, and $T$ was the absolute temperature of the gas, ${ }^{\circ} \mathrm{C}$. The mass of adsorbed gas was:

$m_{\mathrm{a}}=\rho_{\mathrm{ga}} \rho_{c}(1-\phi) \frac{V_{L} b p}{1+b p}$

where $m_{a}$ was the mass of gas adsorbed in the coal matrix, $\mathrm{mg} ; \rho_{g a}$ was the density of gas under standard temperature and pressure, and $\rho_{c}$ was the true density of the coal seam, $\mathrm{mg}$. Thus, the gas quality of the whole coal seam was obtained by adding the gas quality of the two parts as follows:

$m=m_{\mathrm{f}}+m_{\mathrm{a}}=\rho_{g} \phi+\rho_{g a} \rho_{c}(1-\phi) \frac{V_{L} b p}{1+b p}$

$\rho_{c}=\rho \frac{1}{1+0.31 W} \cdot \frac{100-A-W}{100}$

where $\rho$ was the apparent coal body density, $\mathrm{mg} / \mathrm{kg} ; A$ was the coal ash, \%; and $W$ was the coal seam moisture, $\%$.

Since $\phi \ll 1$, the above formula could be simplified to:

$m=\rho_{g} \phi+\rho_{g a} \rho_{c} \frac{V_{L} b p}{1+b p}$

Substituting formulas (15) and (21) into formula (14) could be obtained:

$\frac{\partial\left(\rho_{g} \phi+\rho_{g a} \rho_{c} \frac{V_{L} b p}{1+b p}\right)}{\partial t}-\nabla \cdot\left(\rho_{g} \vec{q}_{g}\right)=I$

Formula (22) was sorted out, and the above parameters were substituted to obtain a fluid-solid coupling model considering the adsorption effect:

$$
\begin{aligned}
& 2\left[\frac{\left[\left(1+M_{0}\right) \phi_{m o}+\alpha\left(M-M_{0}\right)\right]}{1+M}+\phi_{f 0}\right. \\
& \left.+\left(1-R_{m}\right)\left(\Delta \varepsilon_{v}-\Delta \varepsilon_{s}-\alpha \Delta T\right)\right] \frac{\partial p}{\partial t} \\
& +\frac{2 V_{L} b\left(\rho_{\frac{1}{1+0.31 W}} \cdot \frac{100-A-W}{100}\right) p_{a}}{(1+b p)^{2}} \frac{\partial p}{\partial t} \\
& +2 p\left(\frac{\left(\alpha-\phi_{m}\right)}{1+M}+\left(1-R_{m}\right)\right) \frac{\partial \varepsilon_{v}}{\partial t} \\
& +2 p\left(\frac{\left(\alpha-\phi_{m}\right)}{K_{s}(1+M)}-\frac{\left(1-R_{m}\right) \varepsilon_{L} P_{L}}{\left(p+P_{L}\right)^{2}}-\frac{\left(\alpha-\phi_{m}\right) \varepsilon_{L} P_{L}}{\left(p+P_{L}\right)^{2}(1+M)}\right) \frac{\partial p}{\partial t} \\
& -2 p\left[\frac{\left(\alpha-\phi_{m}\right) \alpha_{s}}{1+M}+\alpha_{s}\left(1-R_{m}\right)\right] \frac{\partial T}{\partial t}-\nabla \cdot\left(\frac{k}{\mu} \nabla p^{2}\right)=I
\end{aligned}
$$


The above formula was the coal seam seepage equation of adsorbed gas containing the source and sink term $I$. The permeability $k$ and porosity $\phi$ here varied with the strain, gas seepage and temperature fields, so the seepage field equation not only reflected gas seepage but also the coupling change in the coal seam stress and temperature fields. The solution could be obtained only when the stress field equation, seepage field equation and temperature field equation of coal body were obtained.

\subsection{Temperature field control equation}

The coal seam temperature field control equation could be derived from thermodynamic theory (Zhang et al. 2012; Sun et al. 2007). According to the first law of thermodynamics, the thermal conductivity of coal was as follows:

$\frac{\partial\left(\rho_{s} c_{s} \Delta T\right)}{\partial t}+T \alpha_{s} K \frac{\partial \varepsilon_{V}}{\partial t}+\nabla \cdot\left(k_{s} \nabla T\right)=Q_{T s}$

where $\rho_{s}$ was the coal skeleton density; $\alpha_{s}$ was the coal coefficient of expansion and contraction affected by temperature; $c_{s}$ was the thermal capacity of skeleton in the coal seam; $\mathrm{J} /(\mathrm{mol} \mathrm{K}) ; k_{s}$ was the thermal conductivity of the coal skeleton; $Q_{T s}$ was the strength of the heat source from the coal.

For the heat conduction of gas, on the basis of the energy conservation equation, the following results were obtained:

$\frac{\partial\left(\phi \rho_{g} c_{g} \Delta T\right)}{\partial t}+\nabla \cdot\left(\rho_{g} h_{g} \vec{q}_{g}\right)+\phi \nabla \cdot\left(k_{g} \nabla T\right)=\phi Q_{T g}$

where $\rho_{g}$ was the density of free gas, $\mathrm{kg} / \mathrm{m}^{3} . c_{g}$ was the heat capacity of free gas, $\mathrm{J} ; k_{g}$ was the thermal conductivity of gas; $\phi Q_{T s}$ was the heat source intensity of the gas itself; $h_{g}$ was the specific enthalpy of the gas; $h_{g}=c_{p} \Delta T ; c_{p}$ was generally the specific heat of gas at constant pressure, J.

When it was assumed that the thermally conductive solid and fluid were in thermal equilibrium, Eqs. (24) and (25) were added together to obtain the temperature field control equation of the coal seam:

$$
\begin{aligned}
& \left(\rho_{s} c_{s}+\phi \rho_{g} c_{g}\right) \frac{\partial T}{\partial t}+\Delta T \rho_{g} c_{g} \frac{\partial \phi}{\partial t}+T \alpha_{s} K \frac{\partial \varepsilon_{v}}{\partial t}+\rho_{g} c_{g} \Delta T \nabla \\
& \quad \cdot \vec{q}_{g}+\nabla \cdot\left(k_{t} \nabla T\right) \\
& \quad=Q_{T}
\end{aligned}
$$

Combined with multi-physical field coupling function of COMSOL Multiphysics, the coupling calculation of Eqs. (23) and (26) could be used to analyze the heat-fluidsolid coupling cases.

\section{Numerical modelling of heat injection enhanced drainage in a gas-bearing coal seam}

According to the above-mentioned heat-fluid-solid coupling model, a numerical model was established by using COMSOL Multiphysics to simulate the process of enhancing gas extraction by injecting heat into coal seam boreholes.

\subsection{Numerical model and parameters}

The size of the model was $X \times Y \times Z=50 \mathrm{~m} \times 50 \mathrm{~m} \times$ $10 \mathrm{~m}$. The heat injection borehole was located in the center of the model (the coordinates of the hole on the $y=0$ plane are $x=25, y=0, z=5$ ). Drainage boreholes were arranged side by side on both sides of the heat injection borehole with a distance of $5 \mathrm{~m}$. All boreholes had a radius of $0.1 \mathrm{~m}$ and a length of $30 \mathrm{~m}$, to realize heat injection and gas extraction in coal seam. The periphery and bottom of the model were fixed displacement boundaries, and the upper boundary was a stress boundary. The buried depth of the coal seam was $500 \mathrm{~m}$, and the upper boundary was loaded to simulate the overlying strata gravity. The surrounding, upper and lower boundaries of the model were seepage and thermal insulation boundaries. The initial coal seam pore pressure was $3 \mathrm{MPa}$, and the initial temperature was $30^{\circ} \mathrm{C}$. Considering that the model was symmetrical in $X$ and $Z$ directions, a monitoring line MN was set on the $y=0$ plane to monitor the data, with the endpoint coordinates $M(25,0,5)$ and $N(50,0,5)$, as shown in Fig. 1 . The property parameters of coal and gas in the numerical model were shown in Table 1 . The parameters of coal were tested on the coal specimens sampled from Fangzhuang coal mine in Jiaozuo city, China.

The heat injection temperature was various, and five numerical calculation schemes were designed, namely, no heat injection (keeping the original temperature at $30{ }^{\circ} \mathrm{C}$ ) and heat injection temperature $T_{z}$ at $60{ }^{\circ} \mathrm{C}, 90{ }^{\circ} \mathrm{C}, 120^{\circ} \mathrm{C}$

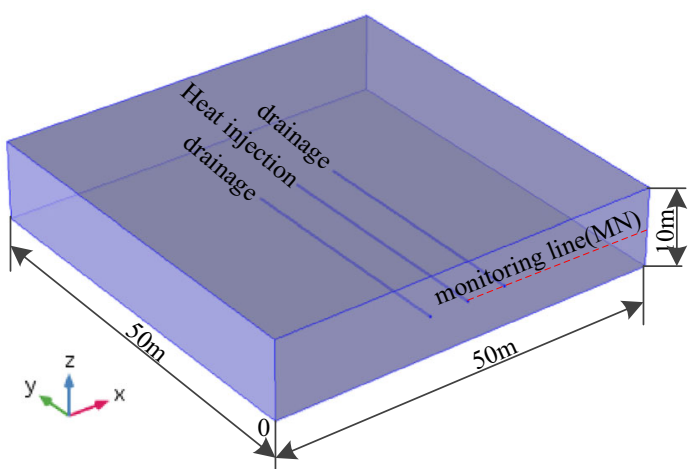

Fig. 1 Numerical model for a typical case of gas drainage in a coal seam 
Table 1 Property parameters in the numerical model

\begin{tabular}{ll}
\hline Property parameter & Value \\
\hline Young's modulus of coal $E(\mathrm{GPa})$ & 3.0 \\
Young's modulus of coal skeleton $E_{s}$ & 9.3 \\
$\quad(\mathrm{GPa})$ & \\
Poisson's ratio of coal $v$ & 0.34 \\
Coal density $\rho(\mathrm{kg} / \mathrm{m})$ & 1400 \\
Langmuir volume constant $V_{L}\left(\mathrm{~m}^{3} / \mathrm{kg}\right)$ & $0.12-0.003 T$ \\
Adsorption constant $b(1 / \mathrm{MPa})$ & $30.12-0.20 \mathrm{~T}+0.000325 T^{2}$ \\
Gas density in standardized status $\rho_{g}$ & 0.72 \\
$\quad(\mathrm{~kg} / \mathrm{m})$ & \\
Coefficient of viscosity $\mu(\mathrm{Pa} \mathrm{s})$ & $1.84 \times 10^{-5}$ \\
Initial porosity of coal seam $\varphi_{m 0}$ & 0.0094 \\
Initial permeability of coal seam $k_{f 0}$ & $1.0 \times 10^{-19}$ \\
$\quad\left(\mathrm{~m}^{2}\right)$ & \\
Specific heat of coal $c_{s}(\mathrm{~J} /[\mathrm{K} \mathrm{Kg}])$ & 1260 \\
Specific heat of gas $c_{g}(\mathrm{~J} /[\mathrm{K} \mathrm{Kg}])$ & 2227 \\
Thermal expansion coefficient $\alpha_{s}(1 / \mathrm{K})$ & $0.1 \times 10^{-6}$ \\
coefficient of heat conduction $k_{t}(\mathrm{~W} /$ & 0.48 \\
$\quad[\mathrm{~m} \mathrm{~K}])$ & \\
Extraction pressure $P_{a}(\mathrm{MPa})$ & 0.018 \\
Langmuir strain constant $\varepsilon_{L}$ & 0.023 \\
Moisture in coal $M(\%)$ & 1.12 \\
Ash content of coal $A(\%)$ & 7.21 \\
\hline
\end{tabular}

and $150{ }^{\circ} \mathrm{C}$. Other conditions of the model remained unchanged.

\subsection{Initial conditions}

Gas and stress initial conditions: when $t=0$, the original coal seam gas pressure $p_{0}(x, y, z)=3 \mathrm{MPa}$. The stress field initial displacement $u_{i}=0(i=1,2,3)$.

Boundary conditions: assuming that the roof and floor are impermeable strata, the boundary conditions of the seepage field were: $p=p_{0}$. Coal seam boundary gas flow $q_{s}=0$. The drainage borehole boundary pressure $p=P_{a}$.

Stress boundary condition: the top boundary of the coal seam $(z=10 \mathrm{~m})$ bears the gravity of the overlying strata of $10 \mathrm{MPa}$.

Displacement boundary conditions: lower boundary $(z=0)$ and surrounding boundaries $(x=0, x=50, y=0$, $y=50)$ are displacement constraints.

Initial conditions of the temperature field: initial coal seam temperature was $T_{0}=30{ }^{\circ} \mathrm{C}$, and the heat injection hole temperature was $T_{z}$ which according to the modelling case.

The unit of calculation time $t$ was d, and the calculation time range was $0-1000 \mathrm{~d}$ for the above five schemes.

\subsection{Numerical modelling results}

\subsubsection{Temperature and gas distribution in the coal seam after heat injection}

Figures 2 and 3 reflected the different coal seam distribution gas pressure periods at $90{ }^{\circ} \mathrm{C}$. The process of gas extraction in a coal seam was shown visually, and the gas pressure in the area closest to the pumping hole decreased rapidly. With the extraction process, the range of gas pressure decreased along the drainage hole, extending to the surrounding area and finally expanding to the whole model range.

At $10 \mathrm{~d}$ after the extraction, the extracted range affected about $3 \mathrm{~m}$ on both sides of the bore hole but the pressure drop value was small, and the pressure was reduced only in the $0.5 \mathrm{~m}$ range of the drilling hole. At $100 \mathrm{~d}$ after the extraction, the extracted range affected about $10 \mathrm{~m}$ on both sides of the borehole. Due to the limited extraction time, the range of pressure reduction was still small. When extracting for $500 \mathrm{~d}$, the pressure of the whole model range decreased and the drainage efficiency was obvious. The pressure dropped by $50 \%$ around $3 \mathrm{~m}$ range of the borehole. It was important to note that the pressure drop on both sides of the extraction bore was not symmetrical due to heat injection (Fig. 3). The pressure value on the left side was obviously lower than the right indicating that temperature affects gas desorption and seepage. High temperature on the left side means more gas desorption and more seepage into the drainage hole. The temperature on the right side was significantly lower than the left because it was farther away from the heat hole (Figs. 4, 5). Gas desorption and seepage flow were also lower than the left side. At $1000 \mathrm{~d}$ after the extraction, the gas pressure distribution form was similar to that of $500 \mathrm{~d}$, but the overall pressure value decreased.

Figures 4 and 5 showed the distribution of temperature values at different times in the coal seam when the heat injection temperature was $90{ }^{\circ} \mathrm{C}$, showing the heat transfer process after injection in the coal seam borehole.

Heat was transferred outward after injection from the heat injection hole. When the heat was injected for $10 \mathrm{~d}$, the rising temperature range was small, affecting only about $2.5 \mathrm{~m}$ around the heat injection hole. When the heat was injected for $100 \mathrm{~d}$, the rising temperature range expands to $15 \mathrm{~m}$, and the temperature of drainage hole that $5 \mathrm{~m}$ away from the heat injection hole increased to about $39.6{ }^{\circ} \mathrm{C}$. When the heat was injected for $500 \mathrm{~d}$, the temperature increased extended to the whole model range and the temperature of the drainage hole increased to $56.7^{\circ} \mathrm{C}$. At $1000 \mathrm{~d}$ of heat injection, the drainage hole temperature increased to $64.6{ }^{\circ} \mathrm{C}$. 


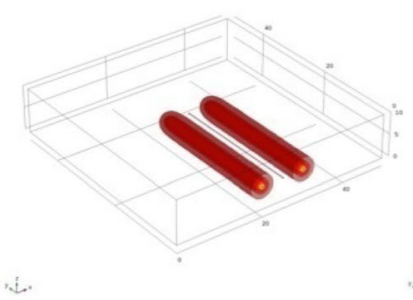

(a) $10 \mathrm{~d}$

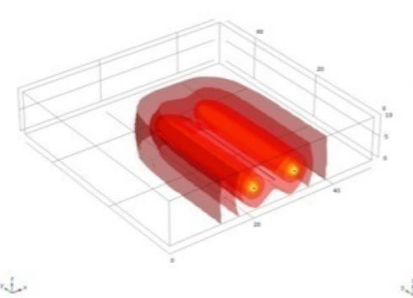

(b) $100 \mathrm{~d}$

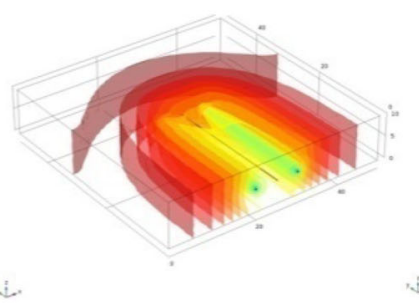

(c) $500 \mathrm{~d}$

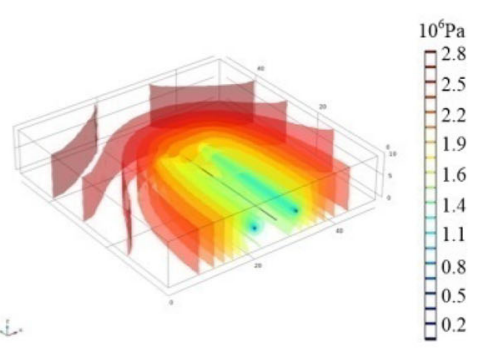

(d) $1000 \mathrm{~d}$

Fig. 2 Gas pressure distribution in a coal seam with heat injection temperature $T_{z}=90{ }^{\circ} \mathrm{C}$

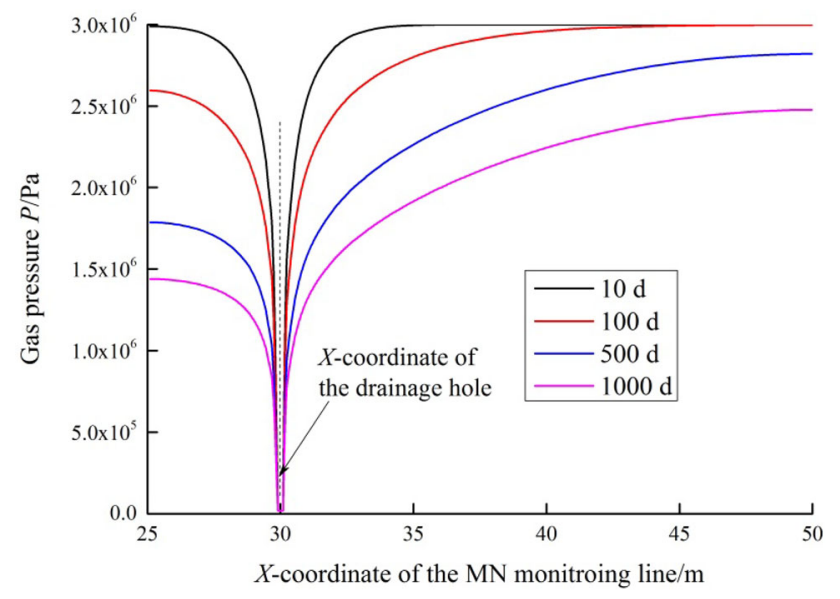

Fig. 3 Gas pressure distribution on the monitoring line $\mathrm{MN}$ with heat injection temperature $T_{z}=90{ }^{\circ} \mathrm{C}$

Figure 6 showed the influence of different heat injection temperatures $T_{z}$ on the temperature distribution in the coal seam. The higher the heat injection temperature, the faster was the heat transfer. When heat was injected at $120{ }^{\circ} \mathrm{C}$ and $150{ }^{\circ} \mathrm{C}$ for $100 \mathrm{~d}$, the temperatures at the extraction borehole were $44.4{ }^{\circ} \mathrm{C}$ and $49.2{ }^{\circ} \mathrm{C}$, respectively. When heat was injected for $500 \mathrm{~d}$, the temperatures at the extraction boreholes reached $70.1{ }^{\circ} \mathrm{C}$ and $83.5^{\circ} \mathrm{C}$, respectively.
Figure 7 showed the distribution of residual gas content in the coal seam after $100 \mathrm{~d}$ and $500 \mathrm{~d}$ of extraction at different heat injection temperatures. It could be seen that the higher the temperature and the longer the extraction time, the lower was the residual gas content in the coal seam.

When the drainage time reached $100 \mathrm{~d}$, the influence range of the drainage borehole was little, limited to about $5 \mathrm{~m}$, and the overall reduction of coal seam gas content was very low. Different heat injection temperatures had a certain influence on the reduction of coal seam gas content. The higher the injection temperature, the greater was the reduction of gas content. However, the influence of temperature was also limited to a small range near the heat injection hole and the drainage hole, and there was almost no difference in the influence of temperature on the gas content of the coal seam beyond the $5 \mathrm{~m}$ on the right side of the drainage hole.

At $500 \mathrm{~d}$ of extraction, the coal seam gas content decreased within the whole model range, and the largest decrease was near the extraction borehole, which was close to $50 \%$ of the original content. The higher the heat injection temperature, the lower was the residual gas content. According to the comparison on different temperature for gas extraction, the residual gas content decreased more significantly when temperature rise from 30 to $60{ }^{\circ} \mathrm{C}$.

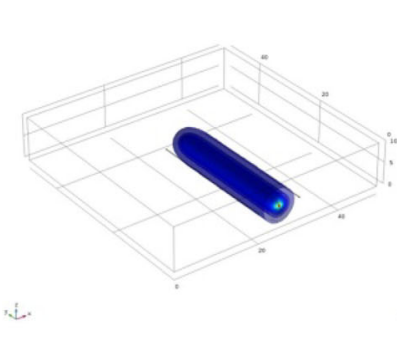

(a) $10 \mathrm{~d}$

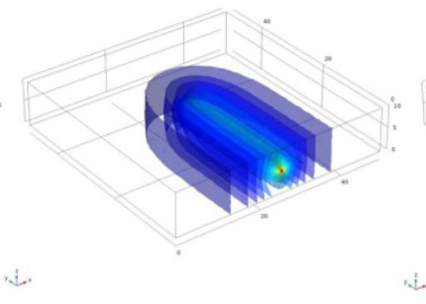

(b) $100 \mathrm{~d}$

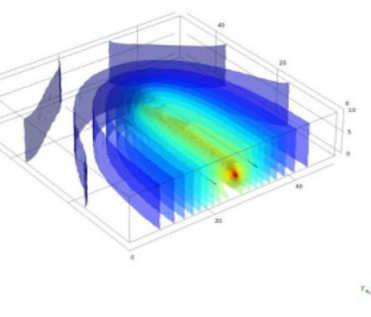

(c) $500 \mathrm{~d}$

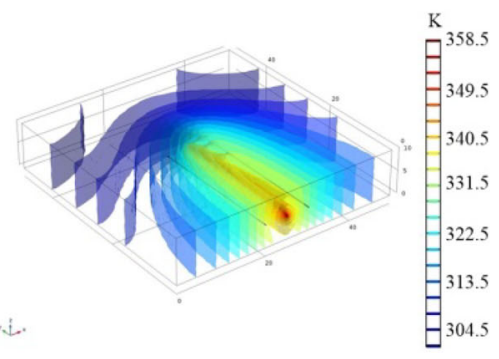

(d) $1000 \mathrm{~d}$

Fig. 4 Temperature distribution in the coal seam with heat injection temperature $T_{z}=90{ }^{\circ} \mathrm{C}$ 


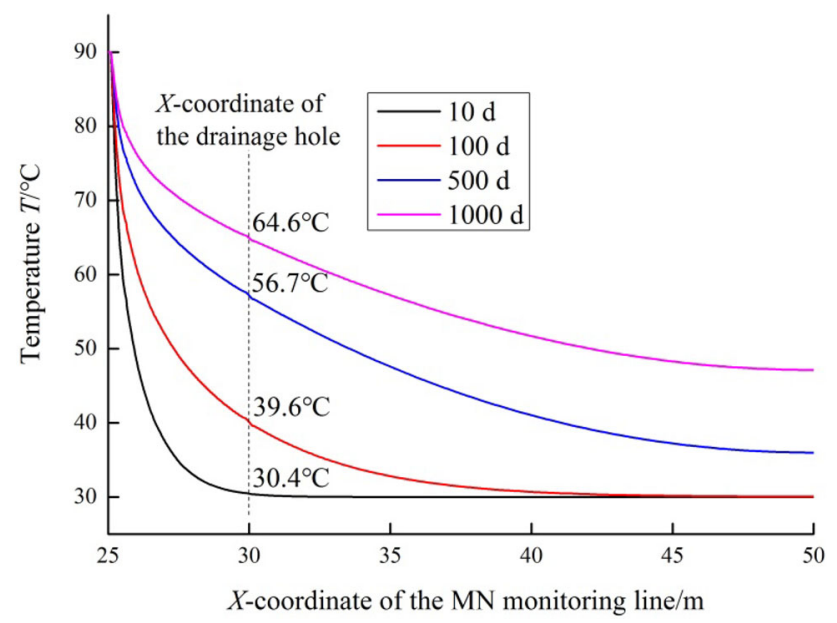

Fig. 5 Temperature distribution on the monitoring line MN with heat injection temperature $T_{z}=90{ }^{\circ} \mathrm{C}$

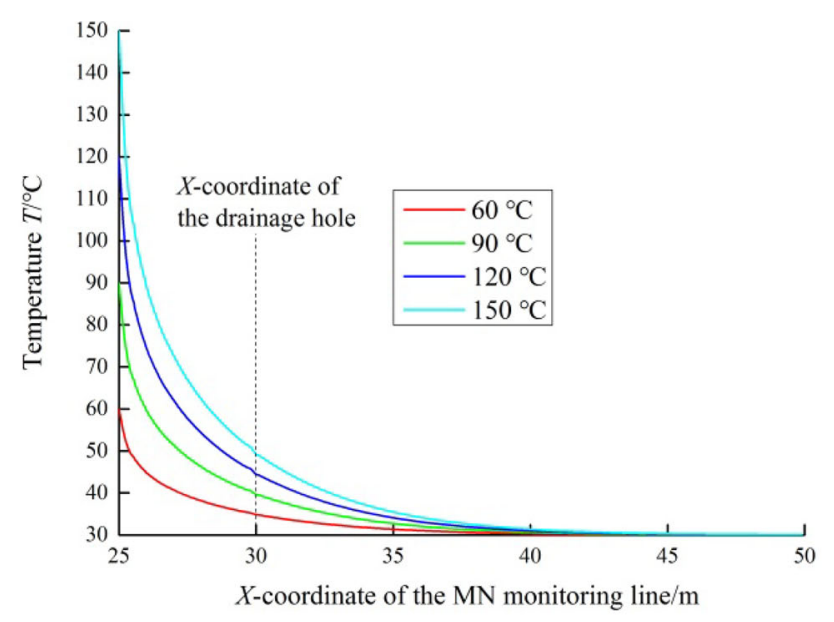

(a) $100 \mathrm{~d}$

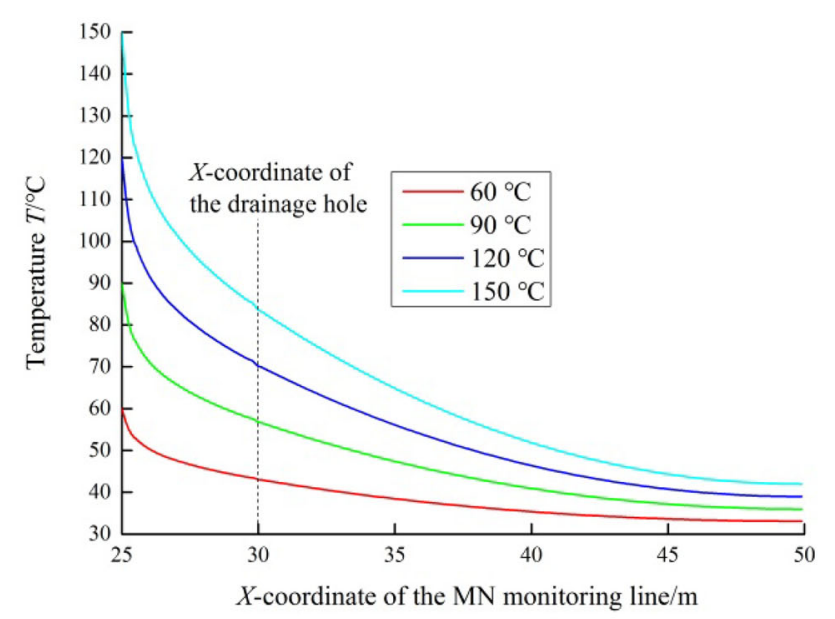

(b) $500 \mathrm{~d}$

Fig. 6 Temperature distribution on the monitoring line $\mathrm{MN}$ with different injection temperatures after $100 \mathrm{~d}$ and $500 \mathrm{~d}$ injection times

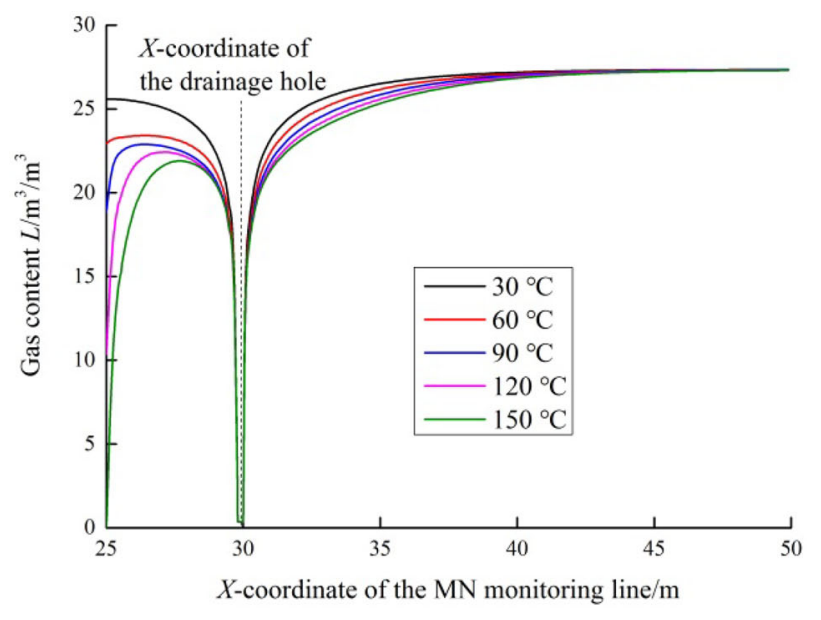

(a) $100 \mathrm{~d}$

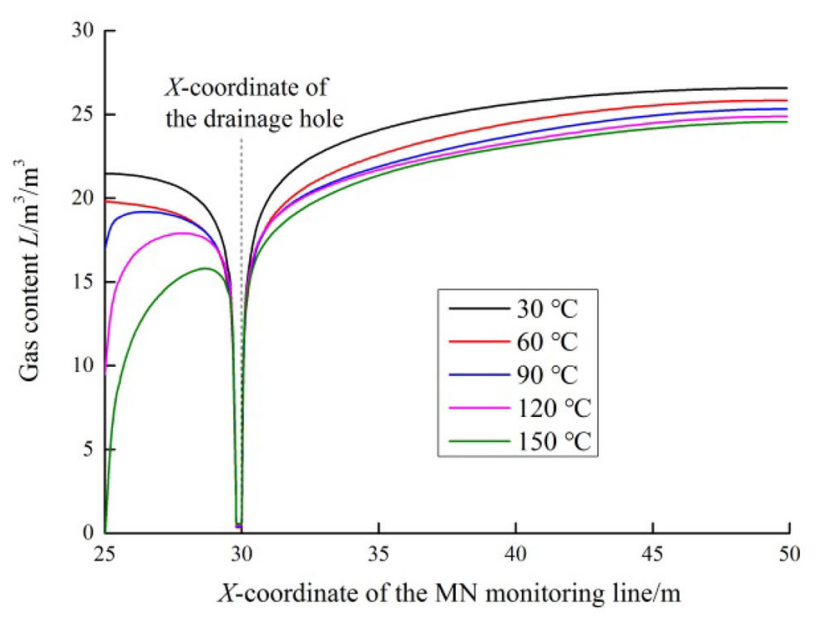

(b) $500 \mathrm{~d}$

Fig. 7 Residual gas content distribution on the monitoring line MN with different injection temperatures after $100 \mathrm{~d}$ and $500 \mathrm{~d}$ injection times

\subsubsection{Effect of injection on the gas extraction rate and accumulative yield}

Figures 8 and 9 showed the influence of heat injection temperatures on the gas extraction rate and cumulative gas extraction capacity. On the whole, the higher the injection temperature $T_{z}$, the higher was the rate of gas output. The drainage rate was largest at the beginning and then gradually decreased. The higher the temperature, the slower the drainage rate decreased. From 30 to $60{ }^{\circ} \mathrm{C}$, the increase of extraction rate was most obvious. For $60{ }^{\circ} \mathrm{C}, 90{ }^{\circ} \mathrm{C}$, and $120{ }^{\circ} \mathrm{C}$ cases, although the extraction rate was still proportional to temperature, the difference was not obvious, especially after the extraction of more than $500 \mathrm{~d}$, the drainage rates were almost no change.

Heat injection had a significant influence on cumulative gas extraction. Within $0-1000 \mathrm{~d}$ of extraction time, the 


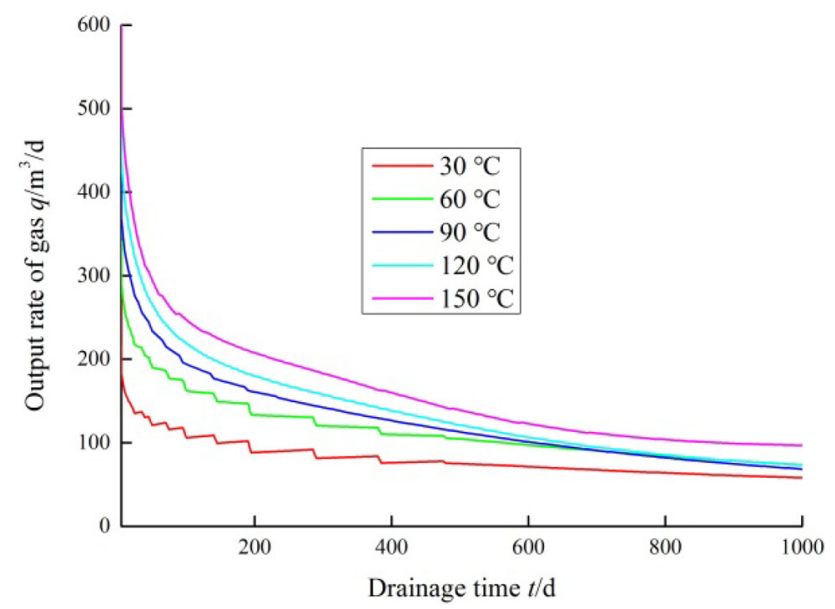

Fig. 8 Output rate of gas versus drainage time

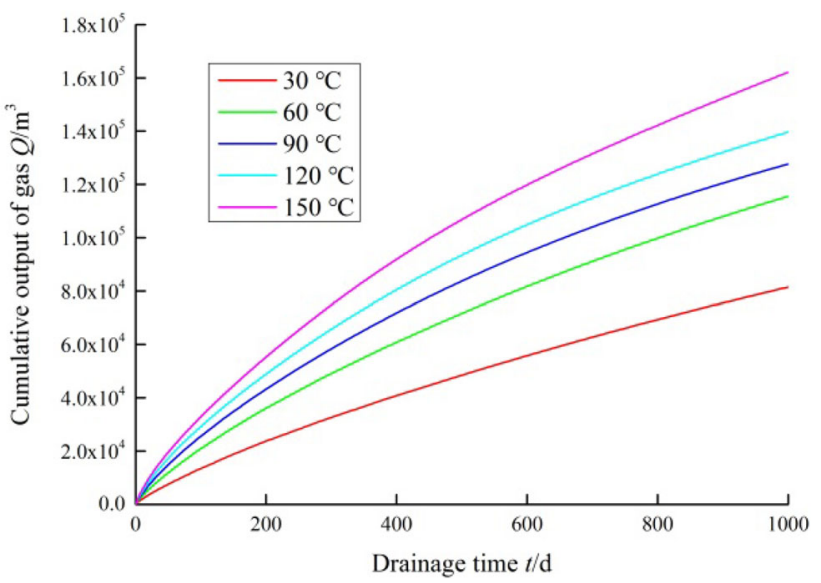

Fig. 9 Cumulative output of gas versus drainage time

higher the temperature, the greater was the cumulative output and the increase in the output gap between different temperatures over time. Because the coal seam gas content was certain, it could be expected that the output would be consistent finally with time, but obviously raising the coal seam temperature greatly improved the gas extraction efficiency. At different temperatures, the output gap of between two cases in was greatest $30^{\circ} \mathrm{C}$ and $60{ }^{\circ} \mathrm{C}$. For examples, when at $100 \mathrm{~d}$ and $500 \mathrm{~d}$, the increasing percentage of gas were $55 \%$ and $47.8 \%$, respectively. By contrast, the gap between $60{ }^{\circ} \mathrm{C}, 90{ }^{\circ} \mathrm{C}$ and $120{ }^{\circ} \mathrm{C}$ were smaller (Table 2).

\subsubsection{Effect of heat injection temperature on gas extraction of coal seams with different permeability rates}

Coal seam permeability is one of the main factors affecting the gas extraction efficiency and yield. The increase in the coal seam temperature will promote gas desorption, but the

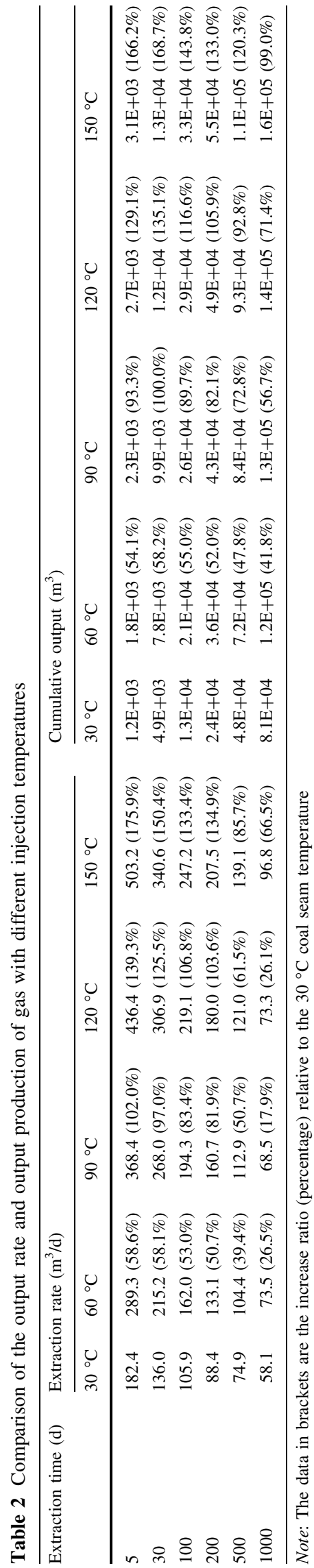




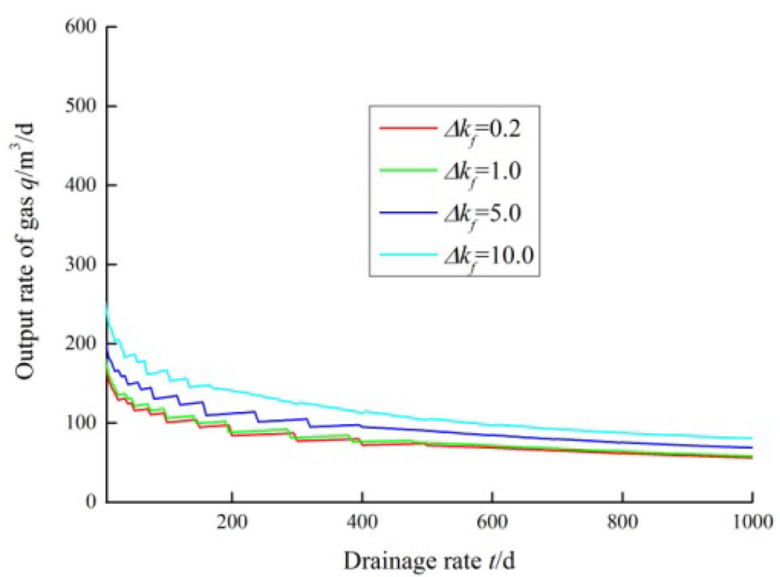

(a) Drainage rate

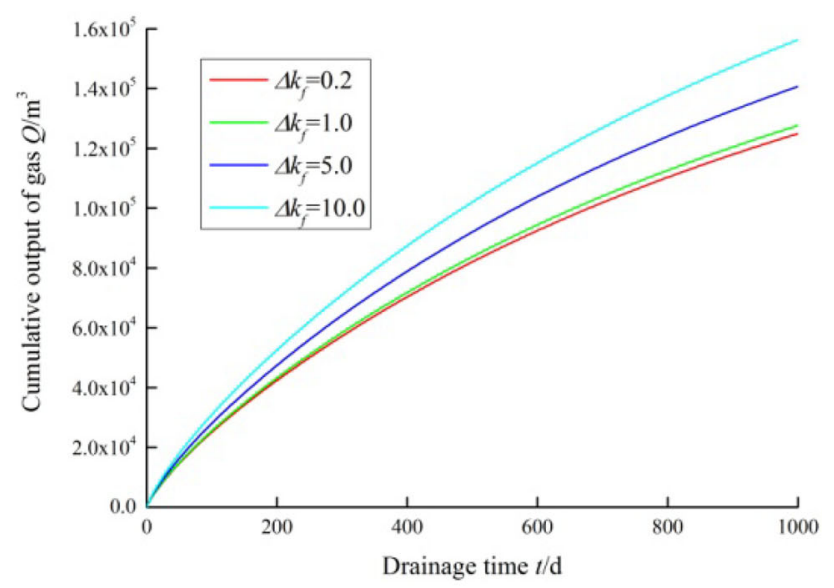

(b) Cumulative drainage volume

Fig. 10 Output rate and cumulative output of gas in coal seams with different permeability (coal seam temperature is $30^{\circ} \mathrm{C}$ )

expansion deformation of the coal matrix caused by the temperature increasing will adversely affect permeability. Therefore, the initial coal seam permeability needs to be changed in the numerical model process.

According to the parameters in Table 1, the initial coal seam permeability $k_{f 0}$ was $1.0 \times 10^{-19} \mathrm{~m}^{2}$. With this permeability as the benchmark to define the relative permeable rate $\Delta k_{f}$, that was, $\Delta k_{f}=k_{f} / 1.0 \times 10^{-19} \mathrm{~m}^{2}$, four cases $\Delta k_{f}=0.2,1,5,10$ were simulated. The drainage rate and cumulative drainage capacity were shown in Figs. 10 and 11 .

When the coal seam temperature was $30{ }^{\circ} \mathrm{C}$ (that was, no heat being injected), the rate of extraction and the cumulative output were proportional to permeability. Because of $1.0 \times 10^{-19} \mathrm{~m}^{2}$ was a typical low permeability level for the coal seam, increasing the permeability would greatly increase the drainage efficiency. When the heat injection temperature was $90{ }^{\circ} \mathrm{C}$, for all coal seams in this research with different permeability, the drainage rate

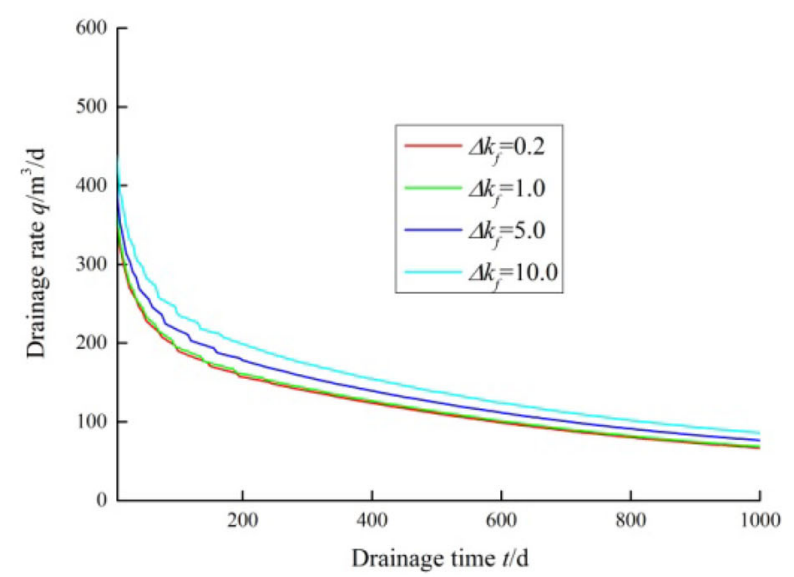

(a) Drainage rate

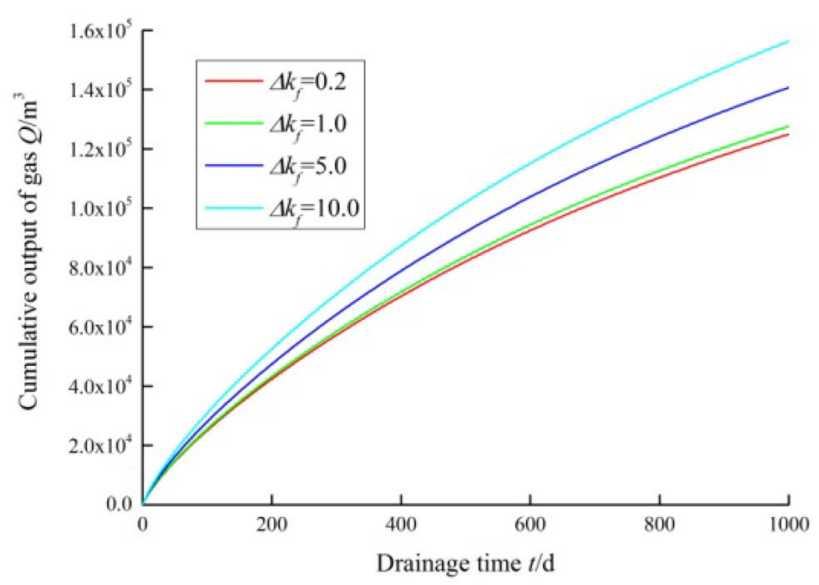

(b) Cumulative drainage volume

Fig. 11 Output rate and cumulative output of gas in coal seams with different permeability (injection temperature is $90{ }^{\circ} \mathrm{C}$ )

increased. The corresponding drainage output were also significantly improved, but the enhancement of coal seam temperature on low permeability was more obvious considering the different permeability between the extraction rate and cumulative output for the relative difference between the reductions.

In order to analyze the influence of heat injection temperature and permeability on the extraction rate in different stages, based on the coal seam temperature of $30^{\circ} \mathrm{C}$ (no heat injection), the relative drainage rate $\Delta q$ was defined as the ratio of the drainage rate at different heat injection temperatures to the drainage rate at $30{ }^{\circ} \mathrm{C}$ at the same drainage time, and this could reflect the change in drainage rate caused by heat injection temperature.

Figure 12 illustrated the relative drainage rate of coal seams with different permeability in three typical time periods as a function of heat injection temperature. Through the simulation, it can be seen that, in a certain range, for coal seams with different permeability, the 


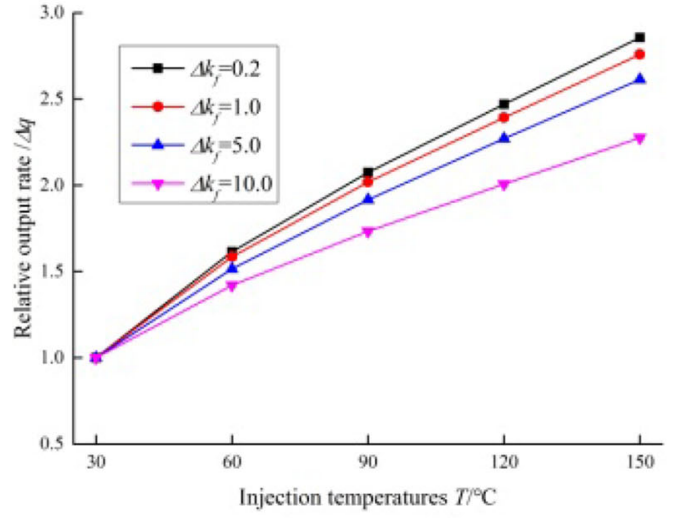

(a) $100 \mathrm{~d}$

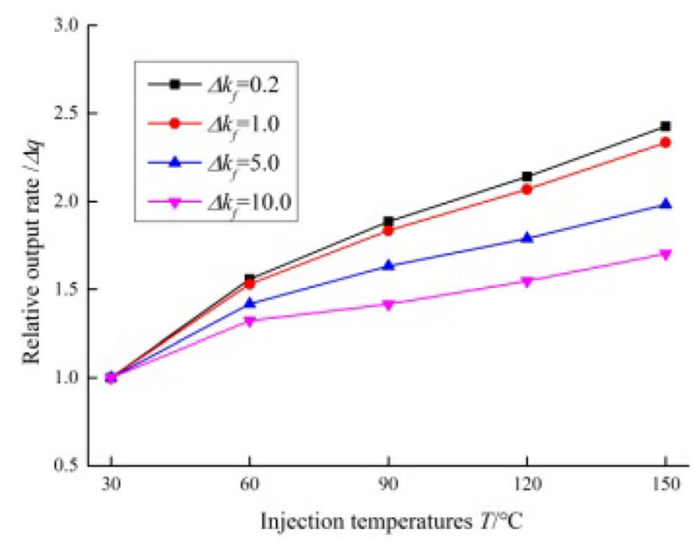

(b) $500 \mathrm{~d}$

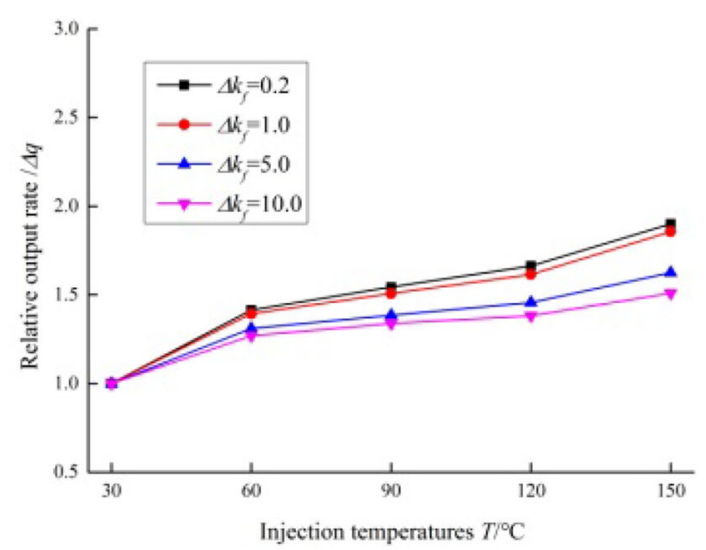

(c) $1000 \mathrm{~d}$

Fig. 12 Relative drainage rate at three typical drainage times in coal seams with different injection temperatures and permeability

production rate can be improved by heat injection. This is due to the increase of temperature leading to the analysis of adsorbed gas and the increase of free coalbed methane concentration. At the same time, the higher the temperature, the smaller the adsorption deformation of the coal body, and the bigger the porosity and fracture opening in the coal body, and the more the permeability of the coal body, so the production rate. Obviously, the temperature increase had a more significant effect on the gas drainage rate in low permeability coal seams. Among the three extraction times selected, the relative drainage rate of the coal seam with the lowest permeability $\left(\Delta k_{f}=0.2\right)$ increased greatest with temperature, and that of the coal seam with the highest permeability $\left(\Delta k_{f}=10\right)$ increased smallest. Compared with different time periods, the slope of the relative drainage rate and temperature curve was biggest in the early extraction period (100 d), and the curve slope gradually decreased with time (500 d and $1000 \mathrm{~d}$ ). The results showed that temperature increasing had the greatest effect on the drainage rate in the initial drainage time, and the effect decreased with time. According to the influence of different temperatures, in the range of $30-60{ }^{\circ} \mathrm{C}$, the curve segment slope was significantly greater than other sections. This reflected that the same amount of energy was used; coal seams where the gas extraction raised from 30 to $60{ }^{\circ} \mathrm{C}$ had the highest efficiency. In the case of continuously increasing coal seam temperature (more than $60{ }^{\circ} \mathrm{C}$ ), the increasing of extraction efficiency was reduced.

\section{Discussions}

A variety of complex multi-field coupling problems were involved in the gas desorption seepage induced by heat injection in coal seams. The deformation of solids under stress, temperature, adsorption, desorption and the effect on permeability were considered and applied to the mathematical model. Although there was a certain difference with real coal seam conditions, the extraction rate and amount calculated numerically did not fully correspond to the real physical values. However, the simulated temperature, coal seam pressure and extraction rate may give some valuable results of in-site engineering.

The results showed that a temperature increase significantly affects the drainage rate but the effect was different in different temperature scope. From 30 to $60{ }^{\circ} \mathrm{C}$, the ratio of drainage efficiency increasing was largest. The energy consumption for increasing drainage rate was smallest. It was no wonder that the result was consistent with previous research (Zhang 2011; Zhao 2012). When the coal temperature increased to $60{ }^{\circ} \mathrm{C}$, the desorption rate increased most obviously. Although the continued increase in coal seam temperature could continuous to increase the drainage efficiency, with the excessive energy consumption and the impact of the mining environment, the difficulties of in-site implementation will be multiplied. Therefore, the coal seam was raised from the original temperature $\left(20-30{ }^{\circ} \mathrm{C}\right)$ to $60{ }^{\circ} \mathrm{C}$ by injecting hot steam and other 
methods, which owned significant advantages, such as saving energy and easy operation while achieving a significant increase in the coal seam gas drainage rate.

The most common technique to extract gas for low permeability coal seams is bedding drilling, the simplest and most effective method to improve the drainage rate is reduce the spacing of drilling holes. Some coal mines' drilling hole spacing, even for 1-2 $\mathrm{m}$ (Zhang 2011; Zhao 2012; Lu et al. 2015), increases the amount of drilling engineering and costs a lot of manpower and resources. However, the achievement was not as expected. Although coal seams are low thermal conductivity substances (thermal conductivity generally in the range of $0.2-0.5 \mathrm{~W} \mathrm{~m}^{-1} \mathrm{~K}^{-1}$ ), with steam injection heating, in about 3 months, the surrounding $5 \mathrm{~m}$ range of the coal seams can be heated to around $60{ }^{\circ} \mathrm{C}$ (Fig. 5). It doesn't take long to heat the coal seam compared with the gas extraction time in coal mines. In addition, according to the simulation results, it is better to improve the drainage rate of low permeability coal seams by injecting hot heating steam. The low permeability coal seam drainage rate attenuation is fast, which is related to the difficulty of gas desorption from coal seam. The coal seams heating are required for a certain period of time, just coincident with the initial easy extraction time. The coal seam heating will slow down the drainage rate attenuation, increase the drainage rate and then enhance the double effect of the drainage output.

\section{Conclusions}

According to solid mechanics theory, the non-linear Darcy's law of seepage and thermodynamics, the existing heat-fluid-solid mathematical model of coal containing gas was improved. The COMSOL Multiphysics software was used to establish a multi-field coupling model to perform the simulation. The process of promoting coal seam gas extraction by injecting heat into boreholes along the coal seam was simulated and analyzed. The following conclusions were obtained:

(1) The multi-physical field coupling model of heat transferring and adsorption in gas-bearing coal seams has been improved and solved by COMSOL Multiphysics. The desorption and seepage process of coal seam gas under the combined action of temperature, stress and adsorption affect can be well simulated to some extent.

(2) In the range of $30-150{ }^{\circ} \mathrm{C}$, gases desorption and seepage flow will be promoted at higher temperatures. The gas drainage rate is proportional to temperature. During the extraction time of
0-1000 d, the increase in gas drainage rate was largest at the initial stage and reduces gradually with time.

(3) Different scope of temperature rise has different effects on increasing the gas extraction rate. From 30 to $60{ }^{\circ} \mathrm{C}$, the ratio of increase is the largest. It will still increase with the temperature rise, but the increase ratio will reduce and there will be a remarkable increase in energy consumption, which will also worsen the in-site environment of underground coal mines.

(4) Comparing the gas extraction by injecting heat into coal seams with different permeability, the results show that the increase in temperature has the more obvious effect on the extraction efficiency of low permeability coal seams.

(5) Although the thermal conductivity of coal is low, injecting atmospheric pressure or pressurized steam into the coal seam will still raise the coal seam temperature within $5 \mathrm{~m}$ range of the hot injection borehole to about $60{ }^{\circ} \mathrm{C}$ in 3 months, which is much less than the gas extraction times in the coal mine. Therefore, coal seam heat injection was considered an efficient auxiliary means of gas extraction, with strong feasibility for low permeability coal seams in China.

Acknowledgements The authors acknowledge the financial support from the Natural Science Foundation of China (U1704131), Program for Science \& Technology Innovation Talents in Universities of Henan Province (18HASTIT018) and the Program for Changjiang Scholars and Innovative Research Team in University (IRT_16R22).

Open Access This article is distributed under the terms of the Creative Commons Attribution 4.0 International License (http://crea tivecommons.org/licenses/by/4.0/), which permits unrestricted use, distribution, and reproduction in any medium, provided you give appropriate credit to the original author(s) and the source, provide a link to the Creative Commons license, and indicate if changes were made.

\section{References}

Alam AKMB, Fujii Y, Fukuda D, Kodama JI, Kaneko K (2015) Fractured rock permeability as a function of temperature and confining pressure. Pure Appl Geophys 172(10):2871-2889

Anderson CJ, Tao W, Jiang JW, Sandler SI, Stevens GW, Kentish SE (2011) An experimental evaluation and molecular simulation of high temperature gas adsorption on nanoporous carbon. Carbon 49:116-125

Esterhuyse S (2017) Developing a groundwater vulnerability map for unconventional oil and gas extraction: a case study from South Africa. Environ Earth Sci 76:626

Ju Y, Wang JG, Wang HJ (2016) $\mathrm{CO}^{2}$ permeability of fractured coal subject to confining pressures and elevated temperature: experiments and modeling. Sci China (Technol Sci) 59(12):1931-1942 
Li XC, Fang ZM (2014) Current status and technical challenges of $\mathrm{CO}^{2}$ storage in coal seams and enhanced coalbed methane recovery: an overview. Int J Coal Sci Technol 1(1):93-102

Li ZQ, Xian XF, Jiang YD, Xu LJ (2009a) Seepage control equation of coalbed methane in geophysical field and its numerical solutions. Chin J Rock Mech Eng 28(S1):3226-3233

Li ZQ, Xian XF, Long QM (2009b) Experiment study of coal permeability under different temperature and stress. J China Univ Min Technol 04:523-527

Li T, Zhang JW, Jin ZP (2017) Numerical research into solid-gasthermal coupling of coal and rock containing gas. J Heilongjiang Univ Sci Technol 27(01):17-21

Lu Y, Shen HM, Qin BT (2015) Gas drainage radius and borehole distance along seam. J Min Saf Eng 32(01):156-162

Shahtalebi A, Khan C, Dmyterko A, Shukla P, Rudolph V (2016) Investigation of thermal stimulation of coal seam gas fields for accelerated gas recovery. Fuel 180:301-313

Shan PF, Lai XP (2018) Numerical simulation of the fluid-solid coupling process during the failure of a fractured coal-rock mass based on the regional geostress. Transp Porous Media 124(3):1061-1079

Sun PD, Yang DQ, Chen YB (2007) Introduction to coupling models for multiphysics and numerical simulations. Science and Technology of China Press, Beijing

Tailakov OV, Tatsienko VP, Kormin AN, Smyslov AI (2015) Efficiency of core samplers in measurement of methane emission in coal beds. J Min Sci 51(6):1203-1207

Teng T, Zhao YX, Gao F, Wang JG, Wang W (2018) A fully coupled thermo-hydro-mechanical model for heat and gas transfer in thermal stimulation enhanced coal seam gas recovery. Int J Heat Mass Transf 125:866-875

Uth HJ (2014) Technical risks and best available technology (BAT) of hydraulic fracturing in unconventional natural gas resources. Environ Earth Sci 72:2163-2171

Wang SG, Elsworth D, Liu JS (2013) Mechanical behavior of methane infiltrated coal: the roles of gas desorption, stress level and loading rate. Rock Mech Rock Eng 46(5):945-958

Wang DK, Wei JP, Fu QC, Liu Y, Xia YL (2015) Seepage law and permeability calculation of coal gas based on Klinkenberg effect. J Cent South Univ 22(5):1973-1978
Wei CH (2012) Damage model for coal and rock under coupled Thermal-Hydraulic-Mechanical conditions and its application. Dissertation, Northeastern University

Yin GZ, Jiang CB, Wang JG, Xu J (2013) Combined effect of stress, pore pressure and temperature on methane permeability in anthracite coal: an experimental study. Transp Porous Media 100(1): $1-16$

Yuan L (2015) Theory and practice of integrated coal production and gas extraction. Int J Coal Sci Technol 2(1):3-11

Zhang LP (2011) Mechanism of coupled Thermal-HydrologicMechanical processes for exploiting coal bed methane in low permeability reservoir and its applications. Dissertation, China University of Mining and Technology

Zhang FJ, Wu Y, Mao XB (2012) Coupled Thermal-HydrologicalMechanical analysis of exploiting coal methane by heat injection. J Min Saf Eng 29(04):505-510

Zhang Q, Sang SX, Zhong LW (2013) Adsorption characteristics and gas storage mechanism of coal seam. Science Press, Beijing

Zhang CL, Xu J, Peng SJ, Zhang XL, Liu XR, Chen YX (2018a) Dynamic evolution of coal reservoir parameters in CBM extraction by parallel boreholes along coal seam. Transp Porous Media 124(2):325-343

Zhang ZT, Zhang R, Wu SY, Deng JH, Zhang ZP, Xie J (2018b) The stress sensitivity and porosity sensitivity of coal permeability at different depths: a case study in the Pingdingshan mining area. Rock Mech Rock Eng 52(5):1539-1563

Zhao D (2012) Study on coalbed methane adsorption and desorption mechanism influenced by coupling of water injection and temperature. Dissertation, Taiyuan University of Technology, Taiyuan

Zhao D, Cai TT, Zhou D, Feng ZC (2018) Isothermal methane adsorption experiments at different temperature stages using the monolayer adsorption principle. Arab J Geosci 11:203

Zhu WC, Wei CH, Liu J, Xu T, Elsworth D (2013) Impact of gas adsorption induced coal matrix damage on the evolution of coal permeability. Rock Mech Rock Eng 46(6):1353-1366 